Eosinophils, chemokines, and neuropeptides are thought to play effector roles in the pathogenesis of allergic diseases such as rhinitis. Eotaxin is a novel $\mathrm{C}-\mathrm{C}$ chemokine with a potent and relatively specific eosinophil chemoattractant activity that binds selectively to CCR3 receptor, however, its activity in inducing eosinophil granules proteins release is poorly characterized. This study was performed to determine whether eotaxin primes eosinophil exocytosis and whether this co-operates with the sensory neuroimmune-axis. In the present communication, we show that $10 \mathrm{ng} / \mathrm{ml}$ eotaxin primed normal human eosinophil for exaggerated eosonophilderived neurotoxin (EDN) release stimulated by $10^{-8}$ M Substance-P (SP). Th is novel priming was blocked by; $7 \mathrm{~B} 11$ and Herbimycin A (HA), the CCR3 antagon ist and the tyrosine kinase inhibitor, respectively. SDSPage studies showed significant tyrosine phosphorylation of several protein residues induced by $10^{-8} \mathrm{M}$ $S P$ only after priming with $10 \mathrm{ng} / \mathrm{ml}$ eotaxin. These results demonstrate a novel co-operation between eotaxin and SP in inducing eosinophil cytotoxicity, which at least in part involves tyrosine kinases pathway $(s)$.

Key words: Allergic inflammation, Eosinophils, Eotax in, SP, EDN, Tyrosine phosphorylation

\section{Novel co-operation between eotaxin and substance-P in inducing eosinophil-derived neurotoxin release}

\author{
Amr El-Shazly ${ }^{\mathrm{CA}}$ and Takeru Ishikawa
}

Kumamoto University, School of Medicine, Department of Otolaryngology, Honjo 1-1-1, Kumamoto 860, Japan

\footnotetext{
${ }^{\mathrm{CA}}$ Corresponding Author

Present Address: Dr Amr El-Shazly, Department of Otolaryngology and Head and Neck Surgery, St George's Hospital - London University, Blackshaw Road, London SW17 OQT, UK
}

Tel/Fax: +441214720478

Email: amr@el-shazly.u-net.com

\section{Introduction}

Allergic rhinitis is a chronic inflammatory disease which is characterized by tissue eosinophilia. A number of allergic mediators act as chemoattractant for eosinophil, however, eotaxin the $\mathrm{C}-\mathrm{C}$ chemokine which selectively binds to CCR3 receptor is a potent and relatively specific eosinophil chemoattractant and its role in rhinitis is well reported. ${ }^{1}$

After tissue infiltration with eosinophils, their cytotoxic function is activated by the proper stimuli to secrete a number of cationic proteins including the major basic protein, the eosinophil peroxidase, the eosinophil cationic protein and the eosinophilderived neurotoxin. The release of these proteins contribute to the hypersensitivity reaction and to tissue damage of the airway. ${ }^{2}$

Among the proper stimuli of EDN release is the neuropeptide SP, which is released from the nasal sensory ne urones. ${ }^{3}$

The current study was designed to investigate whether eotaxin possesses a priming activity for eosinophil exocytosis and whether this works in synergy with SP.

\section{Materials and methods}

\section{Eosinophil purification}

Eosinophils from healthy volunteers were purified from venous blood anticoagulated with heparin by Percoll discontinuous density gradients centrifugation. In short, heparanised blood was sedimented with $6 \%$ dex tran for $30 \mathrm{~min}$ at room temperature. The leukocyte-rich plasma was collected and washed twice with Hank's balanced salt solution (HBSS) containing $2 \%$ fetal bovine serum (FBS). Eosinophils were then separated by Percoll discontinuous gradients centrifugation. Gradients consisted of a mixture of Percoll and HBSS adjusted to $2.5 \mathrm{ml}$ of $78 \%$, $71 \%$ and $56 \%$ Pe rcoll, respectively in $15 \mathrm{ml}$ polystre ne tubes, and recovered cells suspended in HBSS containing $2 \%$ FBS were overlaid. The tubes were then centrifuged at $400 \times g$ for $30 \mathrm{~min}$. The pellet and the lowest band granulocytes were collected, and sedeminted red blood cells were removed by hypodense lysis. These lymphocyte- and monocyte-free granulocytes were incubated with CD16 immunomagnetic beads for $30 \mathrm{~min}$ to eliminate unwanted neutrophils. High purity $>98 \%$ eosinophilic granulocytes were 
obtained by negative selection using magnetic cell sorting. Cell viabilities were $>95 \%$ as judged by trypan blue exclusion.

\section{Eosinophil degranulation and assay of EDN concentration}

Freshly purified eosinophils were suspended in Roswell Park Memorial Institute (RPMI) 1640 medium containing $10 \%$ FBS and adjusted to $1 \times 10^{6}$ cells $/ \mathrm{ml}$. Eosinophil degranulation was induced by dilutions of either $10 \mathrm{ng} / \mathrm{ml}$ eotaxin (Funakoshi Co., Tokyo, Japan), or $10^{-8}$ M SP (Sigma, St Lous, MO) using 96 flat bottom plates (Nunc, Denmark). Briefly, $100 \mu \mathrm{l}$ of each stimulus suspended in the same culture medium as eosinophils (RPMI) were added to $100 \mu \mathrm{l}$ of the purified eosinophil, after $1 \mathrm{~h}$ incubation, supernatants were carefully collected. EDN concentrations in the supernatants were analysed by radioimmunoassay (RIA) using EDN RIA kits (Pharmacia, Uppsala, Sweden). The total content of EDN was measured by lysing eosinophils with $1 \%$ Nonidet P 40 (NP-40). As for the priming experiments, cells were incubated for $15 \mathrm{~min}$ with $10 \mathrm{ng} / \mathrm{ml}$ eotaxin, washed twice, resuspended in the culture medium and their EDN release induced by $10^{-8} \mathrm{MSP}$ was tested in the same way as described above.

\section{Western blotting}

Cells were washed with Hepes-buffered saline containing $1 \mathrm{mMNa}_{3} \mathrm{VO}_{4}(\mathrm{pH} 7.4)$ at $4^{\circ} \mathrm{C}$, and then lysed in triton X-100 lysis buffer (50 mM Hepes, $\mathrm{pH} 7.4,1 \%$ triton X-100, $4 \mathrm{mM}$ EDTA, $100 \mathrm{mM} \mathrm{NaF}, 1 \mathrm{mM}$ $\mathrm{Na}_{3} \mathrm{VO}_{4}, 50 \mu \mathrm{g} / \mathrm{ml}$ aprotinin, $200 \mu \mathrm{M}$ leupeptin, 50 $\mu \mathrm{M}$ pepstatin $\mathrm{A}$, and $1 \mathrm{mM}$ phenylmethylsulfonyl fluoride) at $4^{\circ} \mathrm{C}$ for $30 \mathrm{~min}$. Lysates were subjected to SDS-PAGE and electrotransferred onto polyvinylidene difluoride membranes for western blotting.

\section{Statistical analysis}

Results are expressed as mean \pm SEM and were analysed by paired $t$-test using statview softw are on an apple Macintosh computer. A value of $p<0.05$ was considered significant.

\section{Results and Discussion}

A primer is an agent at non functionally stimulatory dose(s), prepare the cell, making it ready to function to suboptimal dose from the proper stimuli. Accordingly, $10 \mathrm{ng} / \mathrm{ml}$ eotax in was chosen for the following experiments since it is the dose which does not directly induce functional response i.e. EDN release ${ }^{4}$

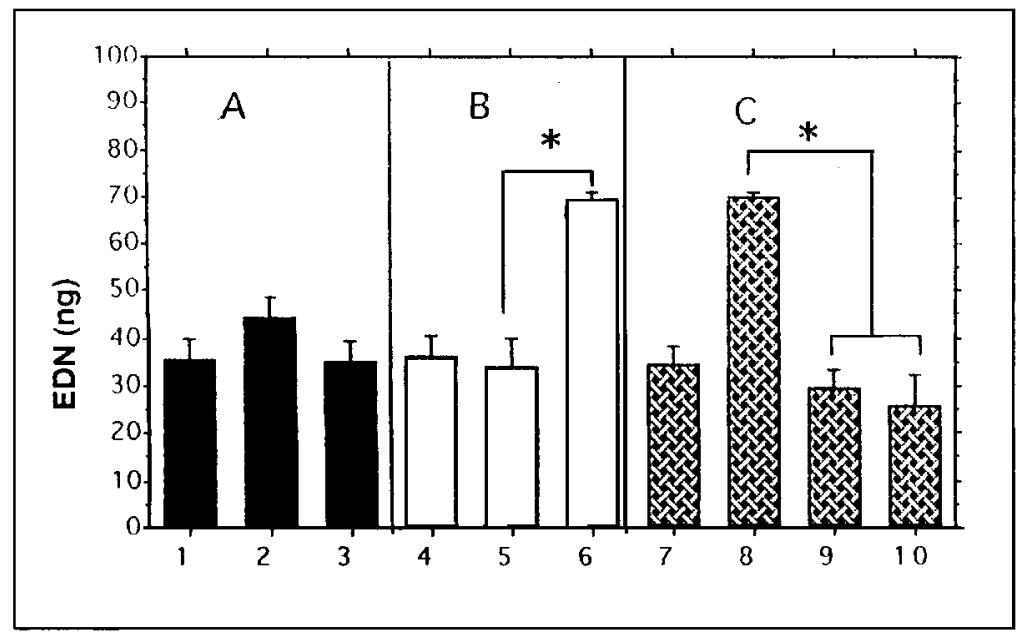

$\begin{array}{llllllllll}\text { Kotaxin } & - & - & + & - & - & + & - & + & + \\ \mathrm{SP} & - & + & - & - & + & + & - & + & + \\ 7 \mathrm{~B} 11 & - & - & - & - & - & - & - & - & + \\ \mathrm{II} \Lambda & - & - & - & - & - & - & - & - & -\end{array}+$

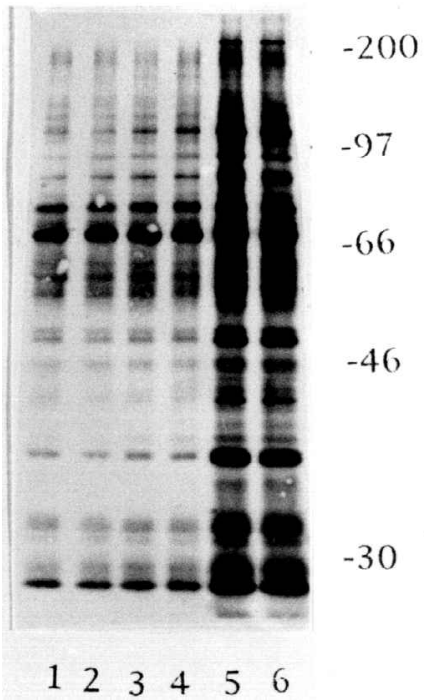

FIG. 1. Relationship between the priming activity of eotaxin in EDN release and tyrosine phosphorylation. (A) EDN secretagouge activity of $10 \mathrm{ng} / \mathrm{ml}$ eotaxin and $10^{-8} \mathrm{M}$ SP. Results are of a $1 \mathrm{~h}$ degranulation assay and represent - SEM of 6 independent experiments performed in duplicate. (B) Priming activity of $10 \mathrm{ng} / \mathrm{ml}$ eotaxin in EDN release stimulated by $10^{-8} \mathrm{M}$ SP. Asterisk indicates $p=0.0001$. Results are of 8 independent experiments performed in duplicate, - SEM. (C) Modulation of eotaxin priming activity in EDN release by 7B11 and herbimycin A. Asterisk indicates $p=0.0001$. Results are of 6-8 independent experiments performed in duplicate, - SEM. (D) Association of tyrosine phosphorylation with CCR3 stimulation. Normal human eosinophils were pre-incubated for $15 \mathrm{~min}$ at $37 ; \mathrm{C}$ with $10 \mathrm{ng} / \mathrm{ml}$ eotaxin (lanes 5 and 6) or for $15 \mathrm{~min}$ with buffer only (lanes 3 and 4), cells were washed three times followed by $10^{-8} \mathrm{M}$ SP stimulation for a further $30 \mathrm{~min}$ at $37 \mathrm{C}$. Lanes 1 and 2 represent control cells stimulated with buffer only. Equal amounts of Triton X-100 cell lysates were analysed by western blotting with $4 \mathrm{G} 10 \mathrm{mAb}$ for phosphorylation. Molecular size markers are indicated on the right $(\mathrm{kDa})$. Experiment shown is one representative of three independent experiments performed in duplicate. 
(Fig. 1A) and thus was ideal for the priming experiments, similarly $10^{-8} \mathrm{M}$ SP which is suboptimal stimulatory dose $\mathrm{d}^{3}$ (Fig. 1A) was tested in the following experiments to demonstrate whether synergy exists between eotaxin and SP. As can be seen in Fig. 1B, $10^{-8} \mathrm{M}$ SP caused a significant EDN release only after the cells were first primed with $10 \mathrm{ng} / \mathrm{ml}$ eotaxin (compare bar 5 with bar 6).

Recently there is increasing evidence that tyrosine kinases are involved in EDN release pathway(s). ${ }^{5}$ Therefore we next blocked CCR3 with 7B11 and tyrosine kinases with herbimycin $\mathrm{A}$, before priming eosinophilwith eotaxin. It was show $n$ that both agents significantly blocked the priming activity of eotaxin (Fig. 1C, compare bars 9 and 10 with bar 8). To further gain insight into the role of tyrosine phosphorylation in eotaxin priming activity, we studied the phosphorylation pattern in normal eosinophils by SP in the same dynamics as the pharmacological assay i.e. in the presence and absence of $10 \mathrm{ng} / \mathrm{ml}$ eotaxin. As can be seen in Fig. 1D, $10^{-8}$ M SP did not induce any tyrosine phosphorylation (Compare lanes 3 and $4 \mathrm{w}$ ith lanes 1 and 2), however, the same dose caused a significant phosphorylation of several protein residues, only after priming the cells with $10 \mathrm{ng} / \mathrm{ml}$ eotaxin (compare lanes 5 and 6 with lanes 3 and 4). It is of note that 10 $\mathrm{ng} / \mathrm{ml}$ eotaxin stimulation did not cause any tyrosine phosphorylation (data not shown).

These findings suggest that low dose eotaxin stimulation of CCR3 may prime human eosinophil cytotoxic functional response against SP through a change in the signal transduction which at least in part involves tyrosine kinases.

We propose that eotaxin at low non functional stimulatory dose primes eosinophil for exaggerated inflammatory response by SP. If so, our data demonstrate a new indirect property of eotax in in activating eosinophil exocytosis and provide a novel model of synergism at the cellular and molecular levels in hypersensitivity disease, which could be a potential target for therapy.

ACKNOWLEDGEMENTS. We are grateful to Drs W. New man, C.R. Mackay and P.D. Ponath (LeukoSite, Inc.) for the gift of 7B11.

\section{References}

1. Minshal EM, Cameron L, Lavigne F, Le ung DY, Hamilos D, Garcia-Zepeda EA, Rothenberg M, Luster AD, Hamid Q. Eotaxin mRNA and protein expression in chronic sinusitis and allergen-induced nasal responses in seasonal allergic rhinitis. Am J Respir Cell Mol Biol 1997; 17: 683-690.

2. Motojima S, Frigas E, Leogering DA, Gleich GJ. Toxicity of eosinophil cationic proteins for guinea pig tracheal epithelium in vitro. Am Rev Respir Dis 1989; 139: 801-805.

3. El-Shazly A, Masuyama K, Ishikaw a T. Mechanisms involved in activation of human eosinophil exocytosis by SP. An in vitro model of sensory neuroimmunomodulation. Im munol Invest 1997; 26: 615-629.

4. El-Shazly A, Masuyama K, Nakano K, Samejima Y, Ishikawa T. Human eotax in induces eosinophil-derived neurotoxin release from normal human eosinophils. Int Arch Allergy Im munol 1998; 117(S1): 55-58.

5. Kato M, Abraham RT, Kita H. Tyrosine phosphorylation is required for eosinophil degranulation induced by immobilized immunoglobulins. $J$ Immunol 1995; 155: 357-366.

\section{Accepted 19 May 1999}




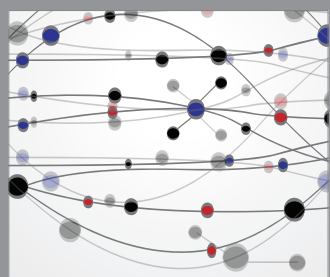

The Scientific World Journal
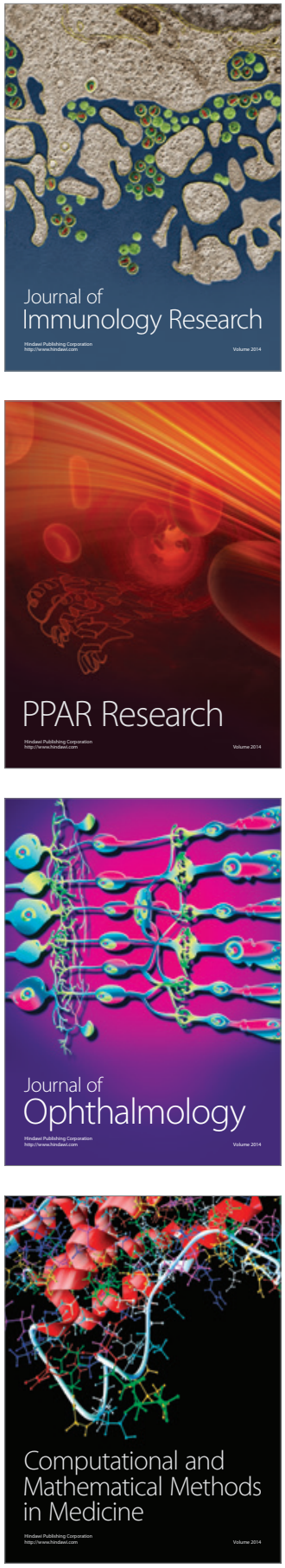

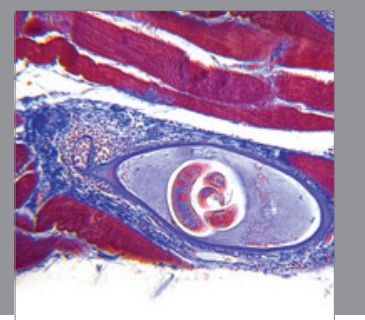

Gastroenterology

Research and Practice
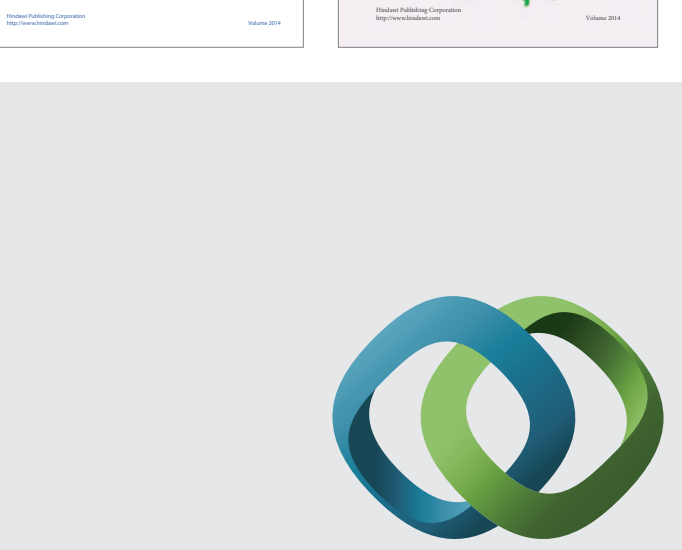

\section{Hindawi}

Submit your manuscripts at

http://www.hindawi.com
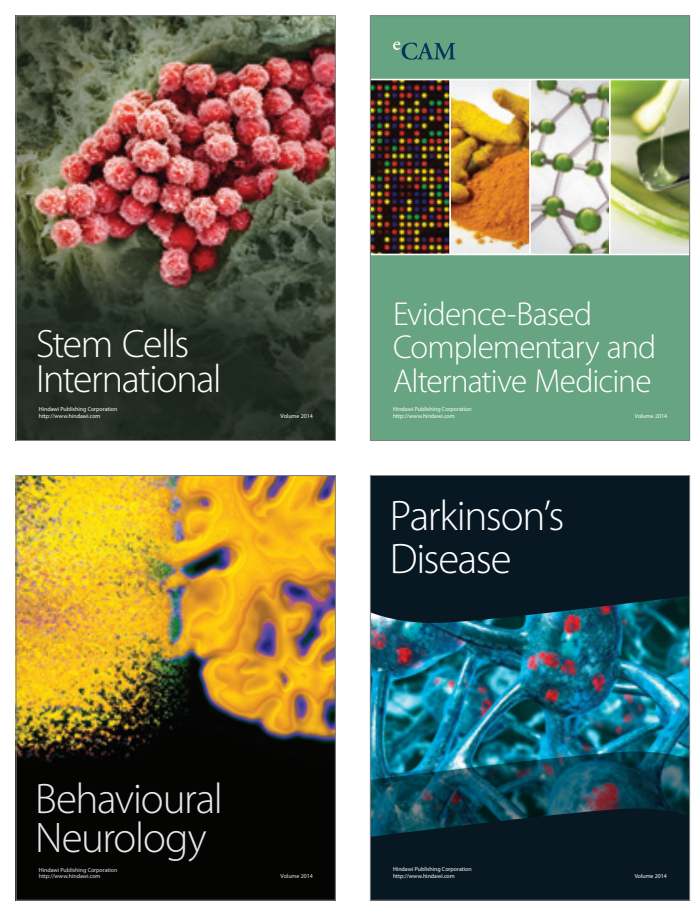

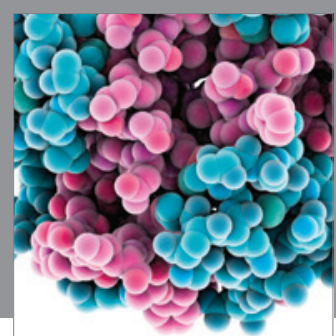

Journal of
Diabetes Research

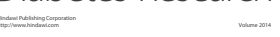

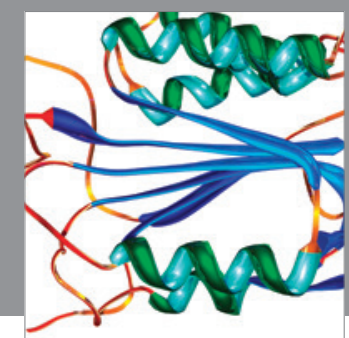

Disease Markers
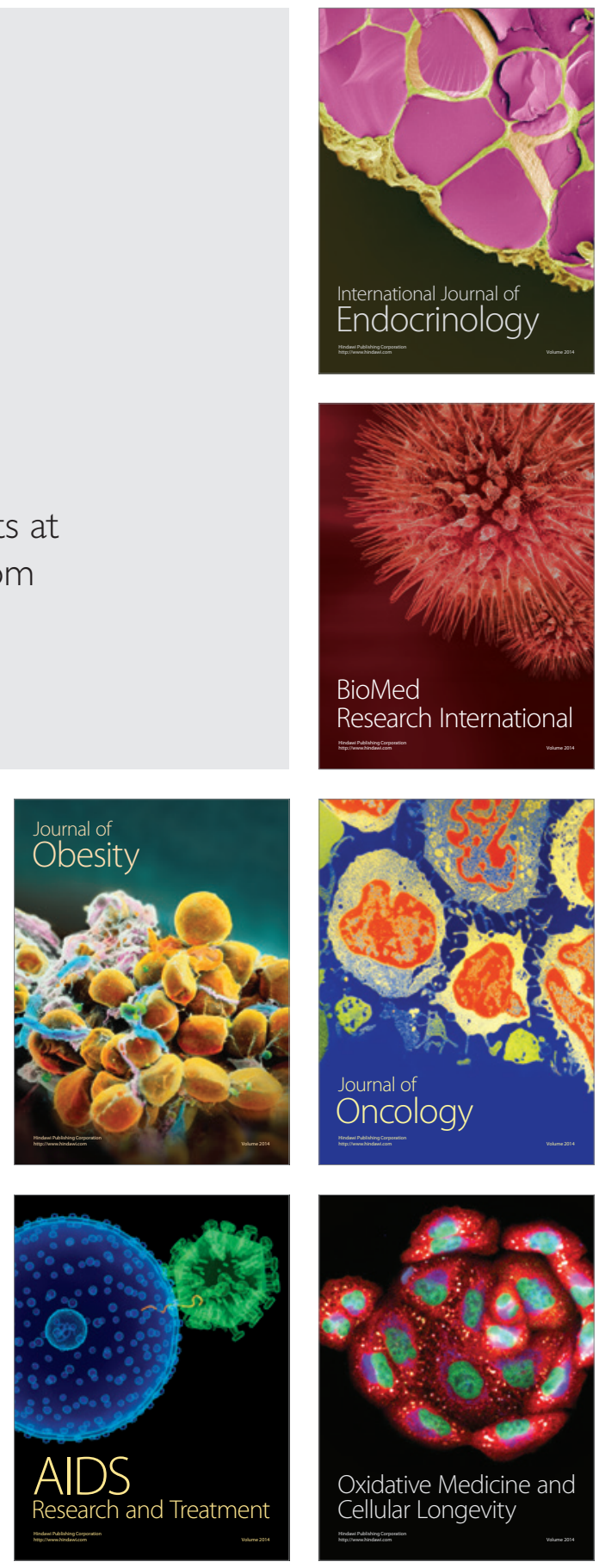